\title{
Ticks infesting humans and associated pathogens: a cross-sectional study in a 3-year period (2017-2019) in northwest Italy
}

Tania Audino ${ }^{1 \dagger}$, Alessandra Pautasso ${ }^{5 \dagger}$, Veronica Bellavia ${ }^{1}$, Valerio Carta ${ }^{1}$, Alessio Ferrari ${ }^{1}$, Federica Verna ${ }^{4}$, Carla Grattarola', Barbara Iulini ${ }^{1}$, Maria Domenica Pintore ${ }^{3}$, Mauro Bardelli ${ }^{3}$, Germano Cassina ${ }^{3}$, Laura Tomassone ${ }^{2}$, Simone Peletto ${ }^{1}$, Valeria Blanda ${ }^{6}$, Alessandra Torina ${ }^{6}$, Maria Caramelli ${ }^{1}$, Cristina Casalone $^{1}$ and Rosanna Desiato ${ }^{1^{*}}$

\begin{abstract}
Background: Tick-borne diseases are common throughout Europe. Ticks transmit pathogens to the host while feeding and together with mosquitoes, they are major vectors of infectious agents worldwide. In recent years, there has been a marked increase in the incidence of tick-bite events and tick-borne disease in northwest Italy, but information on the prevalence of tick-borne pathogens in ticks removed from humans remains scarce. To fill this gap, we report here the prevalence of tick bites and tick-borne pathogens documented for humans in Piedmont, northwest Italy, in the 3-year period 2017-2019.

Methods: Ticks attached to humans during 2017-2019 were collected from residents of urban and rural area by physicians and veterinarians working with local veterinary agencies. All ticks $(n=1290)$ were morphologically identified to the species level. A subset of ticks removed from children (age 0-18 years) and the elderly (> 70 years), both age groups considered to be at-risk populations, was screened by biomolecular analysis to detect pathogens (e.g. Rickettsia spp., Borrelia spp., Anaplasma spp.). Pathogen identity was confirmed by Sanger sequencing.

Results: Ticks were taxonomically assigned to ten species of six genera (Amblyomma, Dermacentor, Haemaphysalis, Hyalomma, Ixodes and Rhipicephalus). Most belonged to the genus Ixodes: 1009 ticks (78.22\%) were classified as Ixodes ricinus. A subset of 500 ticks collected from the two at-risk populations were subjected to PCR assay to determine the presence of Rickettsia spp., Borrelia spp., and Anaplasma spp. The overall prevalence of infection was $22.8 \%$ ( $n=114$; 95\% confidence interval [CI]: 19.19-26.73\%), meaning that at least one pathogen was detected: Rickettsia spp. (prevalence 15\%, $n=76 ; 95 \% \mathrm{Cl} 12.17-18.65 \%$ ); Borrelia spp. (prevalence 6.4\%, $n=32 ; 95 \% \mathrm{Cl} 4.42-8.92 \%$ ); and Anaplasma spp. (prevalence $1.2 \%, n=6 ; 95 \% \mathrm{Cl} 0.44-2.6 \%)$.
\end{abstract}

Conclusions: Our data underline the importance of surveillance in the epidemiology of tick-borne diseases and the implementation of strategies to control tick infestation and associated pathogens.

Keywords: Tick-borne diseases, PCR, Rickettsia spp., Borrelia spp., Anaplasma phagocytophilum

\footnotetext{
${ }^{*}$ Correspondence: rosanna.desiato@izsto.it

${ }^{\dagger}$ Tania Audino and Alessandra Pautasso contributed equally to this work

${ }^{1}$ Istituto Zooprofilattico Sperimentale del Piemonte, Liguria e Valle D'Aosta, Turin, Italy

Full list of author information is available at the end of the article
}

\section{Background}

Ticks are major vectors of zoonotic pathogens in temperate regions [16]. They have a worldwide distribution owing to their ability to adapt to diverse environments, climate zones and host species $[9,17]$. In addition, they

c) The Author(s) 2021. This article is licensed under a Creative Commons Attribution 4.0 International License, which permits use, sharing, adaptation, distribution and reproduction in any medium or format, as long as you give appropriate credit to the original author(s) and the source, provide a link to the Creative Commons licence, and indicate if changes were made. The images or other third party material in this article are included in the article's Creative Commons licence, unless indicated otherwise in a credit line to the material. If material is not included in the article's Creative Commons licence and your intended use is not permitted by statutory regulation or exceeds the permitted use, you will need to obtain permission directly from the copyright holder. To view a copy of this licence, visit http://creativeco mmons.org/licenses/by/4.0/. The Creative Commons Public Domain Dedication waiver (http://creativecommons.org/publicdomain/ zero/1.0/) applies to the data made available in this article, unless otherwise stated in a credit line to the data. 
transmit a variety of pathogens of medical and veterinary importance (e.g. viruses, bacteria, protozoans, helminths) that are responsible for a diverse range of infections, commonly referred to as tick-borne diseases (TBDs) [38]. Many TBDs are zoonoses, such as rickettsiosis, Lyme borreliosis, anaplasmosis [1] and tick-borne encephalitis (TBE), which may remain asymptomatic or manifest with potentially life-threatening involvement of the central nervous, the integumentary or the vascular system. Children, the elderly and the immunosuppressed are at higher risk of developing severe illness.

Rickettsiosis is a bacterial disease caused by obligate, intracellular $\alpha$-proteobacteria of the genus Rickettsia. These Gram-negative, pleomorphic bacteria are prevalent in Sicily, Sardinia, Latium, and Calabria regions of Italy. Until 2002, Rickettsia conorii conorii, identified as the causal agent of Mediterranean spotted fever (MSF), was the only pathogenic Rickettsia species in Italy. A number of new Rickettsia species have since been identified by molecular analysis which have been described and recognized as causative agents of human disease in Europe. Twenty-six Rickettsia species with validated and published names are currently reported worldwide [29].

Spirochetes of the complex Borrelia burgdorferi (s.l.) are the etiological agent of Lyme borreliosis. Lyme disease typically presents as an erythema migrans rash and non-specific symptoms (e.g. fatigue, fever, headache, muscle and joint pain), but if left untreated it can progress to multisystemic disease. Though rarely fatal, deaths linked to Lyme carditis have been reported [35] (Kugeler et al. 2011). The disease is prevalent in Friuli-Venezia Giulia, Veneto, Trentino-Alto Adige (all regions in northeast Italy), Liguria (northwest Italy) and Emilia-Romagna (central Italy), whereas B. burgdorferi is reported only sporadically in both humans and ticks in the south-central regions of Italy and the islands (EpiCentro; https://www.epicentro.iss.it/zecch e/borreliosi).

Anaplasma phagocytophilum is responsible for granulocytic anaplasmosis. It may be asymptomatic or cause non-specific symptoms (e.g. fever, headache, muscle ache). The fatality rate is $<1 \%[2,11]$.

The worldwide incidence of TBDs has increased [9] in parallel with the survival and spread of vectors. Local climatic factors (macro- and microclimate) in addition to environmental factors can facilitate the appearance or reappearance of vector-borne diseases in a given area [17]. The distribution and prevalence of TBDs are closely related to climate factors, primarily high and low temperature extremes and precipitation patterns. Climate change can modify weather patterns, leading to an increase in extreme events and disease outbreaks by altering biological variables, including vector population size and density, vector survival rates, relative abundance of reservoir hosts and pathogen reproduction rates [14]. Collectively, these changes can increase the risk of pathogens being transmitted to humans.

The Mediterranean regions have a remarkable geographical and wildlife diversity, with high environmental variability resulting from the influence of altitude and distance from the sea. The variability of environmental characteristics favors the formation of tick populations. Italy has more tick species (about 40 species; [21]) than any other European country, including Portugal [32] and the UK [34, 37]. By virtue of its geographical extension from the Alps in the north to the Mediterranean in the south, Italy has a wide range of diverse habitats and given its geographical location in the north/south migration path of wild birds from Africa to Europea, it provides a port of entry for the arrival of new pathogens.

The incidence of human TBDs in Italy is likely underestimated due to poor surveillance and the limited number of available studies. Since 2011, the Istituto Zooprofilattico Sperimentale of Piedmont, Liguria and Valle d'Aosta (IZS PLVA), a public health agency, has conducted TBD surveillance in Italy. Ticks are identified morphologically to the species level and subjected to biomolecular analysis (PCR) for the detection of Rickettsia spp., Borrelia spp. and Anaplasma spp. Here, we report data from surveillance carried out during the 3-year period 2017-2019 in northwest Italy. The data will be used for further risk assessment.

\section{Methods}

\section{Tick collection and identification}

A total of 1290 ticks were collected, of which a subsample from two at-risk populations (children aged $<18$ years and adults aged $>70$ years) were tested for the presence of pathogens of the genera Rickettsia, Borrelia and Anaplasma. Most samples $(n=1254)$ came from the geographical areas falling under the administration of IZS PLVA or from people who had traveled abroad $(n=12)$ or were from neighboring regional areas $(n=14)$; some were of unknown origin $(n=10)$. All specimens were kept in $70 \%$ undenatured alcohol or frozen at $-20{ }^{\circ} \mathrm{C}$ and sent to the IZS PLVA laboratories for analysis. Species identification was performed using appropriate taxonomic keys [12] for each developmental stage (larvae, nymphs, adult female or male).

\section{Molecular analysis \\ DNA extraction}

Tick DNA was extracted from adults, nymphs or larvae. Each microtube containing a tick was filled with either $350 \mu \mathrm{l}$ (larvae and nymphs) or $600 \mu \mathrm{l}$ (adults) of 
phosphate buffered saline solution ( $\mathrm{pH}$ 7.2). The ticks were then homogenized using a Savant FastPrep FP120 cell disrupter (Thermo Fisher Scientific, Waltham, MA, USA) for $45 \mathrm{~s}$ at maximum speed $(6.5 \mathrm{~m} / \mathrm{s})$. After homogenization, the microtubes were centrifuged (MIRKO 22R; Andreas Hettich GmbH \& Co. KG, Tuttlingen, Germany) for $10 \mathrm{~min}$ at $14,000 \mathrm{rpm}$, and $150 \mu \mathrm{l}$ of the supernatant was used for total DNA extraction with a QIAamp DNA Mini kit with an automated QIAcube protocol and following the manufacturer's instructions (Qiagen, Hilden, Germany).

\section{PCR assays}

The PCR assays were performed in a total volume of $25 \mu \mathrm{l}$ according to previously published protocols $[7,22,36]$ for the detection of Rickettsia spp., Borrelia burgdorferi (s.l.) complex and Anaplasma spp. PCR amplification was followed by gel electrophoresis on $2 \%$ agarose and visualization with GelRed staining under UV light. The target genes, primer sequences and expected amplicon sizes are reported in Table 1.

\section{DNA sequencing}

The PCR products were purified using a QIAquick Gel Extraction kit (Qiagen). The cycle sequencing reaction was following the protocol of the BrilliantDye Terminator v.3.1 kit (NimaGen, Nijmegen, The Netherlands; $1 \mu \mathrm{l}$ BrilliantDye v 3.1, $3.5 \mu \mathrm{l} 5 \times$ sequencing buffer, $1 \mu \mathrm{l}$ template, $1 \mu \mathrm{l}$ primer $5 \mathrm{pMol}, 13.5 \mu \mathrm{l}$ water) using the PCR primers for sequencing. The cycle sequencing reactions were purified with an AutoSeq G-50 Dye Terminator Removal kit (GE Healthcare, Chicago, IL, USA). Sanger sequencing was carried out by capillary electrophoresis using a 3130XL Genetic Analyzer (Applied Biosystems, Foster City, CA, USA). Obtained sequences were compared using the basic local alignment search tool (BLAST) provided by the National Center for Biotechnology (http:// blast.ncbi.nlm.nih.gov/), with sequence records available in GenBank for confirmation of pathogen identification and species assignment.

\section{Statistical analysis}

Statistical analysis was performed using Stata Statistical Software, Release 15.1 (StataCorp LP, College Station, TX, USA), including creation of tables and calculation of prevalence. QGIS 2.18, a geographic information system application, was used to visualize and create the map showing the tick distribution in the three regions of the country. A non-parametric test was employed to investigate the association between tick number and bite frequency. As the distribution of number of ticks was skewed, the median test (StataCorp LP) was applied. Covariates showing a significant association with the number of ticks were categorized and entered into a subsequent linear regression model after log-transformation of the dependent variable (number of ticks).

\section{Results}

A total of 1290 ticks were collected from humans in the period 2017-2019 and morphologically identified, of which 239 (18.5\%), 624 (48.4\%) and 427 (33.1\%) were collected in 2017, 2018 and 2019, respectively. A peak in the number of ticks was observed in 2018 due to a persistent warm spell in the spring (warm and wet weather conditions; https://www.arpa.piemonte.it/rischinaturali/temat ismi/clima/rapporti-di-analisi/annuale_pdf/anno_2018. pdf). The median test showed a statistically significant difference in the number of ticks collected per year $(P=0.001)$, as the multivariate regression model demonstrated $(P=0.002)$.

The ticks were taxonomically assigned to ten species of six genera: Amblyomma, Dermacentor, Haemaphysalis, Hyalomma, Ixodes, Rhipicephalus (Table 2). Most ticks were morphologically identified as Ixodes ricinus (78.22\%). Since some ticks (12.3\%) of the genus Ixodes were damaged during collection (e.g. missing rostrum), we were unable to classify these specific ticks to the species level. We identified one Amblyomma parvum tick from a man who had traveled abroad and was bitten in Brazil, and one Hyalomma marginatus tick from a man bitten in Greece.

Ordered by life stage, the nymph stage was the most frequent life stage $(59.8 \%$; $95 \%$ confidence interval $[\mathrm{CI}]$ :

Table 1 Molecular detection of tick-borne pathogens: target genes, primer nucleotide sequences, amplicon size

\begin{tabular}{|c|c|c|c|c|}
\hline Species & Target gene & Nucleotide sequence $\left(5^{\prime}-3^{\prime}\right)$ & Amplicon size (bp) & Reference \\
\hline Rickettsia spp. & ompB & $\begin{array}{l}\text { GTAACCCGGAAGTAATCGTTTCGTAA (forward) } \\
\text { GCTTTATAACCAGCTAAACCACC (reverse) }\end{array}$ & 511 & [7] \\
\hline Borrelia burgdorferi (s.l.) & Flagellin & $\begin{array}{l}\text { AGAGCAACTTACAGACGAAATTAAT(forward) } \\
\text { CAAGTCTATTTTGGAAAGCACCTAA (reverse) }\end{array}$ & 482 & [36] \\
\hline Anaplasma phagocytophilum & msp2 & $\begin{array}{l}\text { CCAGCGTTTAGCAAGATAAGAG (forward) } \\
\text { GMCCAGTAACAACATCATAAGC (reverse) }\end{array}$ & 334 & {$[22]$} \\
\hline
\end{tabular}


57.03-62.46), followed by adult females (28.9\%; 95\% CI: 26.45-31.47), larvae (2.3\%; 95\% CI: $1.57-3.30)$ and adult males (0.7\%; 95\% CI: 0.32-1.32). The median test demonstrated a significantly greater proportion of nymphs $(P<0.05)$, as shown in the multivariate regression model (Table 3).

In terms of the percentage of ticks that tested positive for one or more pathogen according to life stage, we found that $61 \%$ of the positive ticks were nymphs, $32 \%$ were females, $3 \%$ were larvae and $1 \%$ were males.

People reported most often receiving a bite on the limbs (43\%), followed by the trunk (21\%) and the head or neck (especially children) (12\%). The median test showed a statistically significant difference for bite site $(P<0.05)$, while the linear regression model demonstrated that the legs were bitten more often than other body sites ( $P=0.001$ for lower limbs, $P=0.03$ for limbs; Table 3$)$. Most people reported being bitten while walking in the woodlands $(40 \%)$ or in a garden, lawn, park (46\%); the remaining $14 \%$ reported being bitten in other locations, such as the beach, train, others. Most tick-bite events occurred while the person was in the woodlands or in garden, lawn or park.

The median test demonstrated the presence of a statistically difference in tick number by habitat $(P=0.005)$. The regression model revealed in a loss of statistical significance for woodlands $P=0.057)$, but not for garden, lawn, park $(P=0.002)$ (Table 3$)$. The least often bitten were the elderly (124 ticks collected in the 3 -year period; Table 4), but the difference was not statistically significant (median test, $P=0.098$ ).

A total of 500 ticks (i.e. the total number of ticks collected from the two at-risk populations) underwent biomolecular analysis for pathogen detection. The ticks were analyzed as single sample or pooled; pools were composed of ticks of the same species and collected from the same individual. Overall, 114 ticks (22.8\%; 95\% CI: 19.19-26.73\%) tested positive for one or more pathogens. Most samples testing positive for Borrelia, Rickettsia or Anaplasma $(n=71)$ came from the province of VerbanoCusio-Ossola (northeast Piedmont), an area with a high tick population, although the prevalence by province was higher for the provinces of Cuneo and Biella (36.84 and $30.77 \%$, respectively) (Table 5).

Of these 500 ticks analyzed, 76 were positive for Rickettsia spp. (15\%; 95\% CI: 12.17-18.65\%), and sequencing analysis identified the species as $R$. helvetica $(n=31$; $I$. ricinus: $n=3$ larvae, $n=16$ nymphs, $n=7$ adult females; Ixodes sp.: $n=4$ nymphs, $n=1$ adult female); $R$. monacensis $(n=35$; I. ricinus: $n=23$ nymphs, $n=11$ adult females; Ixodes spp. $n=1$ adult female); $R$. slovaca $(n=4$; I. ricinus: $n=2$ nymph, $n=1$ adult female; Dermacentor marginatus $(n=1$ adult female)); $R$. aeshlimannii
Table 2 Tick species collected from humans in the period 20172019 and morphologically identified

\begin{tabular}{lll}
\hline Tick genus & Tick species & $\begin{array}{l}\text { Number } \\
\text { of ticks/ } \\
\text { species }\end{array}$ \\
\hline Ixodes & I. ricinus & 1009 \\
& I. hexagonus & 13 \\
& I. frontalis & 1 \\
& I. acuminatus & 1 \\
Total number Ixodes ticks & Ixodes spp. & 158 \\
Rhipicephalus & & 1182 \\
& R. sanguineus & 2 \\
Total number Rhipicephalus ticks & Rhipicephalus spp. & 6 \\
Dermacentor & & 8 \\
Amblyomma & D.marginatus & 6 \\
Haemaphysalis & A.parvum & 1 \\
Hyalomma & H.punctata & 3 \\
Not determined & & 1 \\
\hline
\end{tabular}

( $n=1$ Rhipicephalus sanguineus adult male); Rickettsia spp. ( $n=5$; I. ricinus: $n=5$ nymphs). Six ticks were positive for Anaplasma phagocytophilum ( $n=6$; I. ricinus nymphs; $1.2 \%$; 95\% CI: 0.44-2.59\%).

In comparison, 32 tick samples were positive for Borrelia burgdorferi (s.l.) (6.4\%; 95\% CI: 4.44-8.95\%). Sequencing and BLAST identified the genospecies as: B. afzelii ( $n=11$; I. ricinus: $n=6$ nymphs, $n=3$ adult females; Ixodes spp.: $n=2$ adult females); B. burgdorferi (s.s.) $(n=1 ;$ I. ricinus nymph), B. garinii $(n=3 ; I$. ricinus nymph), $B$. lusitaniae $(n=4$; I. ricinus: $n=1$ nymph, $n=3$ adult females) and $B$. valaisiana ( $n=2$ adult females) (Tables 6, 7).

Two pathogens were detected in four samples (coinfections): Anaplasma phagocytophilum + Rickettsia monacensis; Borrelia afzelii $+R$. helvetica; $B$. burgdorferi (s.s) $+R$. monacensis; B. lusitaniae $+R$. monacensis.

Seventeen ticks were weakly positive by PCR, and sequencing was not successful; only the pathogen genera were assigned in these cases.

\section{Discussion}

The main findings of the present study are the prevalence and the distribution of tick species and tick-borne pathogens collected from humans in northwest Italy. Most samples were collected from children, often bitten by nymphs and females, whereas fewer samples came from the elderly. Males ticks (I. ricinus) feed as larvae and nymphs but take only occasional, small blood meals as adults. Their occurrence in humans is uncommon 
Table 3 Results of the multivariate regression model

\begin{tabular}{|c|c|c|c|c|}
\hline Number of ticks (log) & Coefficient & Standard error & $P$ value & 95\% Confidence intterval \\
\hline \multicolumn{5}{|l|}{ Life stage } \\
\hline Larvae & 0.12 & 0.09 & 0.19 & -0.06 to 0.30 \\
\hline Nymph & 0.25 & 0.04 & $0.000^{*}$ & 0.16 to 0.34 \\
\hline Female & 0.08 & 0.05 & 0.067 & -0.01 to 0.17 \\
\hline Male & -0.10 & 0.14 & 0.467 & -0.36 to 0.17 \\
\hline \multicolumn{5}{|l|}{ Year of collection } \\
\hline 2018 & 0.10 & 0.03 & $0.002^{*}$ & 0.04 to 0.17 \\
\hline 2019 & 0.11 & 0.04 & $0.002^{*}$ & 0.04 to 0.18 \\
\hline \multicolumn{5}{|l|}{ Habitat } \\
\hline Garden, lawn, park & 0.15 & 0.05 & $0.002^{*}$ & 0.05 to 0.25 \\
\hline Urban site & -0.14 & 0.18 & 0.442 & -0.49 to 0.21 \\
\hline Country side & -0.06 & 0.28 & 0.834 & -0.61 to 0.49 \\
\hline Woodlands & 0.09 & 0.05 & 0.057 & 0.00 to 0.19 \\
\hline Other & -0.05 & 0.07 & 0.524 & -0.19 to 0.10 \\
\hline \multicolumn{5}{|l|}{ Bite site } \\
\hline Trunk & 0.07 & 0.04 & 0.089 & -0.01 to 0.15 \\
\hline Upper limbs & -0.07 & 0.05 & 0.135 & -0.17 to 0.02 \\
\hline Lower limbs & 0.14 & 0.04 & $0.001^{*}$ & 0.06 to 0.22 \\
\hline Limbs & 0.67 & 0.23 & $0.003^{*}$ & 0.22 to 1.12 \\
\hline Other & -0.02 & 0.07 & 0.818 & -0.14 to 0.11 \\
\hline Not determined & -0.06 & 0.08 & 0.465 & -0.22 to 0.10 \\
\hline _cons $^{* *}$ & -0.20 & 0.07 & 0.005 & -0.34 to -0.06 \\
\hline
\end{tabular}

*Statistically significant at $P<0.05,{ }^{* *}$ Intercept

Table 4 Number of ticks by age group (humans) and developmental stage and sex (ticks); n.d. not determined

\begin{tabular}{|c|c|c|c|c|c|c|}
\hline \multirow[t]{2}{*}{ Age group (years) } & \multicolumn{6}{|c|}{ Life stage } \\
\hline & Larvae & Nymphs & Female & Male & n.d. & Total \\
\hline$\leq 18$ & 22 & 321 & 78 & 4 & 25 & 450 \\
\hline $18-50$ & 2 & 211 & 99 & 2 & 32 & 346 \\
\hline $51-69$ & 4 & 199 & 117 & 2 & 36 & 358 \\
\hline$\geq 70$ & 2 & 34 & 75 & 0 & 13 & 124 \\
\hline Not determined & 0 & 6 & 4 & 1 & 1 & 12 \\
\hline Total & 30 & 765 & 369 & 8 & 106 & 1290 \\
\hline
\end{tabular}

[39]. Almost all pathogens were detected in I. ricinus, the primary vector of TBD, as reported elsewhere [3, 17]. Numerous studies have been conducted in northeast Italy, a region that is under continuous surveillance for ticks and associated TBDs $[5,8,13]$, whereas surveillance in northwest Italy has been patchy and somewhat limited in terms of defining TBD epidemiology [10, 30].

Here, we report data from a 3-year survey of ticks and tick-borne pathogens circulating throughout northwest Italy. Our data show a wide distribution of tick-borne pathogens and a considerable prevalence in some provinces, such as Cuneo (southwest Piedmont), Biella and
Verbano-Cusio-Ossola (both northeast Piedmont). The number of cases of TBD is likely associated with the high number of tick populations; further analysis of climatic and host factors is needed to better understand the dynamics of tick populations and their pathogens.

Ixodes ricinus, one of the most abundant tick species in Italy, is an important vector of infection. In our study, it ranked as the most frequently detected and most common species collected from humans. This finding is shared by a previous study reporting that I. ricinus was widespread in woodland areas of northwest Italy, where Ixodes ticks find optimal conditions of temperature 


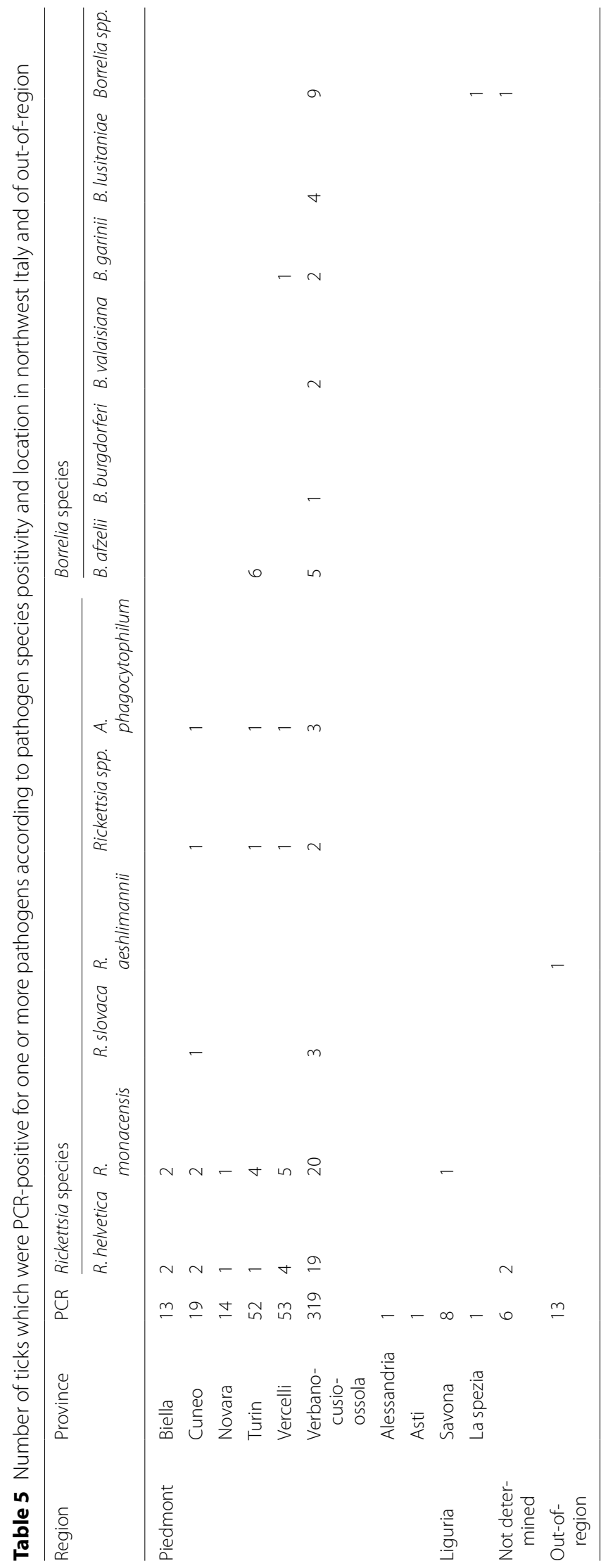


Table 6 Number of tick species identified and number and percentage of positive samples of each tick species for one or more pathogens

\begin{tabular}{llll}
\hline Tick species $(n)$ & \multicolumn{3}{l}{ Number of ticks positive for pathogens (\%) } \\
\cline { 2 - 4 } & Rickettsia spp. & Borrelia spp. & Anaplasma spp. \\
\hline Ixodes ricinus (1009) & 68 & 23 & 6 \\
Ixodes hexagonus (13) & 0 & 0 & 0 \\
Ixodes frontalis (1) & 0 & 0 & 0 \\
Ixodes acuminatus(1) & 0 & 0 & 0 \\
Ixodes spp. (158) & 6 & 2 & 0 \\
Rhipicephalus sanguineus & 1 & 0 & 0 \\
(2) & & & \\
Rhiphicephalus spp. (6) & 0 & 0 & 0 \\
$\begin{array}{l}\text { Dermacentor marginatus } \\
\text { (6) }\end{array}$ & 1 & 0 & 0 \\
Amblyomma parvum (1) & 0 & 0 & 0 \\
Haemaphisalys punctata & 0 & 0 & 0 \\
(3) & & 0 & 0 \\
Hyalomma marginatum & 0 & 7 & 0 \\
(1) & & Total 32 & Total 6 \\
Not determined (89) & 0 & Total 76 & \\
Total (1290) & &
\end{tabular}

Table 7 Number and percentage of ticks that tested positive for different pathogens.

\begin{tabular}{ll}
\hline Pathogen (no. of ticks analyzed = 500) & $\begin{array}{l}\text { Number of tick } \\
\text { samples testing } \\
\text { positive (\%) }\end{array}$ \\
\hline Rickettsia helvetica & $31(6.2)$ \\
Rickettsia monacensis & $35(7.0)$ \\
Rickettsia slovaca & $4(0.6)$ \\
Rickettsia aeshlimannii & $1(0.2)$ \\
Rickettsia spp. & $5(1.0)$ \\
Borrelia afzelii & $11(2.2)$ \\
Borrelia burgdorferisl & $1(0.2)$ \\
Borrelia garinii & $3(0.6)$ \\
Borrelia lusitaniae & $4(0.8)$ \\
Borrelia valaisiana & $2(0.4)$ \\
Borrelia spp. & $11(2.2)$ \\
Total Borrelia spp. & $32(6.4)$ \\
Anaplasma phagocytophilum & $6(1.2)$ \\
\hline
\end{tabular}

$\left(20-23{ }^{\circ} \mathrm{C}\right)$ and relative humidity (85-98\%) for their development [40]. Despite their small size, the majority of ticks were nymphs (60\%), in line with findings reported by Otranto et al. [28], and thus may be easily overlooked [41].

Rickettsia was the most frequently detected pathogen genus, with 76 Rickettsia-positive ticks out of the 500 tested (prevalence 15\%; 95\% CI: $12.17-18.65 \%$ ); this finding is in line with a previous study carried out in Italy [6]. Rickettsia conorii conorii, comprising a variety of genospecies, is considered to be the main etiologic agent of MSF. MSF is widely distributed through southern Europe, Africa and the Middle East, where it is an emerging or re-emerging disease in some areas. Sequencing of genetic markers has led to the molecular characterization of strains and the identification of many new Rickettsia spp. or subspecies within the spotted fever group involved in human rickettsiosis [19]. In our study, sequencing revealed four Rickettsia species ( $R$. helvetica, $R$. monacensis, R. slovaca, $R$. aeschlimanni). Rickettsia monacensis was first isolated in Germany and is now widespread throughout Europe in I. ricinus tick vectors. In Italy, it was isolated in Sardinia [20], Sicily and Liguria [28] from I. ricinus and Dermacentor marginatus.

Previous studies have associated $R$. helvetica with perimyocarditis [24], fever and skin rash [25] and, more recently, with subacute meningitis [26]. Its main carrier is I. ricinus and its prevalence varies across Europe [27]. To date, it has been isolated in north Italy (Liguria, Veneto, Friuli-Venezia-Giulia, Trentino) from I. ricinus [28].

On the other hand, $R$. slovaca was previously largely isolated in the south of Italy (Sicily, Basilicata, Puglia) and in Liguria from $R$. sanguineus and D. marginatus $[4,28]$. It is implicated in tick-borne lymphadenopathy (TIBOLA) and Dermacentor-borne necrosis erythema and lymphadenopathy (DEBONEL). Here we report one case of $R$. slovaca infection in $D$. marginatus; it was also identified in two $I$. ricinus ticks.

Rickettsia aeshlimanni has been identified in tick species Hyalomma marginatum and I. ricinus [29] and potentially in new species (D. marginatus and $H$. lusitanicum). In Europe, $R$. aeshlimanni mainly infects ticks of the genus Hyalomma; the pathogenicity of this bacterium is not well understood, although MSF-like lesions have been reported [15]. It has been isolated in Sicily, Latium and Tuscany from $H$. marginatum [4, 33]. Here, we report for the first time the isolation of $R$. aeshlimannii from Rhipicephalus sanguineus in Capoliveri (Tuscany 2018). We also found Anaplasma phagocytophilum in $I$. ricinus.

Regarding Borrelia burgdorferi (s.l.), our findings indicate a low prevalence. Sequencing identified five genomic groups of the B. burgorferi (s.l.) complex: B. afzelii, B. burgdorferi (s.s.), B. garinii, B. lusitaniae and B. valaisiana. Three of these genomic groups are considered pathogenic for humans: B. afzelii is mainly associated with skin manifestations; $B$. burgdorferi (s.s.) is the agent of Lyme arthritis; and $B$. garinii is the only species linked to neuroborreliosis [31]. Borrelia lusitaniae and B. valaisiana are of uncertain pathogenicity. Our study adds new knowledge about the distribution of the genospecies of 
the $B$. burgdorferi complex, which is a pathogen of ecological and epidemiological interest.

The ecological and climatic conditions of northwest Italy are conducive to tick persistence and spread, which means greater exposure of the population to tick bites. Peak tick activity occurs in the spring and summer when the climatic conditions are favorable for tick reproduction, and reports of tick-bite events increase in these seasons as more people visit woodlands for recreation (Fig. 1). Our data show variation in the number of ticks collected per year (range: 239-624 samples), which probably reflects climatic conditions, since sampling was irregular during the course of the 3 years. While 2017 was quite a dry year, rainfall in the spring and summer of 2018 was abundant (May 2018 was recorded as the seventh wettest month since 1958 (http://www.arpa.piemo nte.it/rischinaturali/bacheca-archivio/bacheca-archivio. html). The summer temperatures, which remained within the average range (http://www.arpa.piemonte.it/risch inaturali/widget/servizi-siti-web-regione.html?delta $=0$ ) created ideal conditions for greater parasitic environmental pressure. The result was an increase in tick-bite events in humans between May and July 2018. Similarly, the highest number of tick-bite events was recorded in May and June of 2019. The early peak in collected ticks recorded for May of 2017 probably stemmed from the warm and wet weather conditions in the area from February to April (https://www.arpa.piemonte.it/rischinatu rali/tematismi/clima/rapporti-di-analisi/annuale_pdf/ anno_2017.pdf). Most tick-bite events occurred during a walk in the woodlands, which is an ideal habitat for $I$. ricinus. Numerous events were recorded also in urban areas according to the data collected by physicians.

The identification of tick pathogens in $24 \%$ of the samples underlines the importance of surveillance, prevention and correct diagnosis in humans. The increase in the prevalence and transmission of TBD raises concern for public health. The geographic spread of tick species driven by changes in micro- and macroclimate, human activities, land use, vector population growth and many other factors has brought about an increase in TBD. As we continue to discover new species of bacteria, it is essential to monitor the emergence of new and existing pathogens. Tick surveillance and tracking can enhance our understanding of tick spread and ecology and identify areas of risk for disease transmission.

It is also important to raise awareness in the population as personal protective strategies can help in the prevention of TBD. Exposure to ticks may also result from exposure to domestic and companion animals that bring ticks into the house. Tick prevention using repellents and tick checks after domestic animal exposure are simple risk reduction measures. As novel ticktransmitted pathogens are discovered and emerge in geographic regions, our ability to detect, describe and understand this growing public health threat must step up to meet the challenge (Fig. 2).

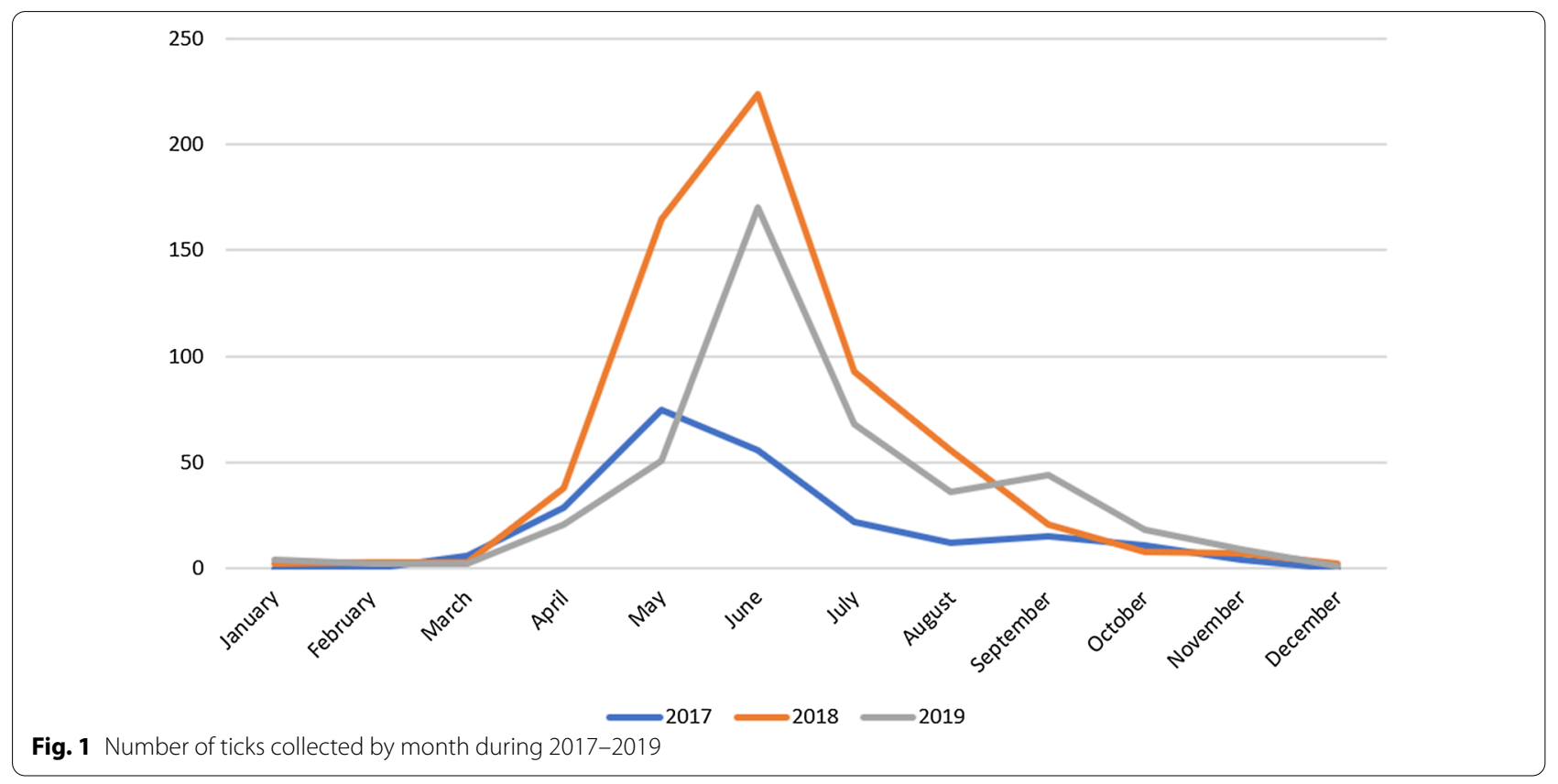



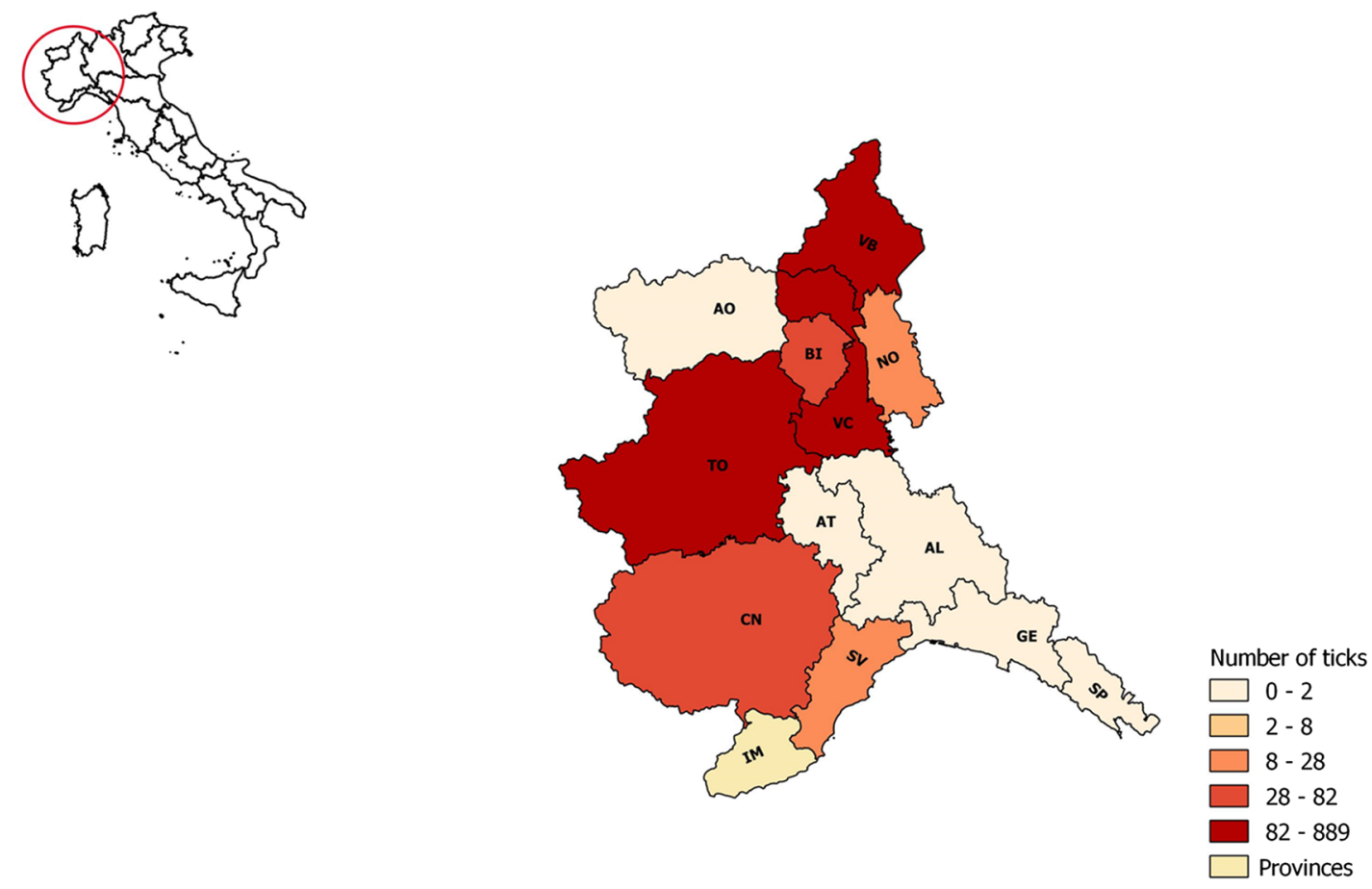

Fig. 2 Map showing the geographic distribution (\%) of ticks collected in northwest Italy

\section{Conclusions}

The risk of TBD in humans is associated with local tick abundance, infection prevalence, density of vertebrate reservoir hosts, and climate change. Our data show that humans bitten by ticks in northwest Italy are at risk of infection from diverse pathogens. Co-infected ixodids were also detected, indicating that more than one pathogen may be transmitted by the same tick bite with potential for multiple infections in humans. Local information campaigns are essential for prevention and protection against TBD. Further analysis of these factors may help in assessing risks and guide the implementation of public health policies against TBD.

\section{Abbreviations}

IZS PLVA: Istituto Zooprofilattico Sperimentale of Piedmont, Liguria and Valle d'Aosta; MSF: Mediterranean Spotted Fever; TBDs: Tick-borne diseases; TBE: Tick-borne encephalitis.

\section{Acknowledgements}

Not applicable.

\section{Authors' contributions}

TA and AP analyzed the data and wrote the manuscript. VB carried out DNA extraction. AF and FV performed molecular investigations on the parasites. VC CG and BI carried out tick identification. MDP, MB and GC collected ticks from humans and submitted these for analysis. SP performed Sanger sequencing for PCR confirmation. VB and AT performed molecular analysis for confirmation at the species level of pathogens. LT, MC and CC critically revised the manuscript. RD carried out the statistical analysis and supervised the study. All authors read and approved the final version of the manuscript.

\section{Funding}

Funding for the study was provided by the Italian Ministry of Health (grants 19CEA, IZS PLV 15/16 RC) and by the Cassa di Risparmio di Torino bank foundation (grant 19D01).

\section{Availability of data and materials}

The datasets used and/or analyzed during the current study are available from the corresponding author on reasonable request.

\section{Ethics approval and consent to participate}

Not applicable.

\section{Consent for publication}

Not applicable.

\section{Competing interests}

The authors declare that they have no competing interests.

\section{Author details}

${ }^{1}$ Istituto Zooprofilattico Sperimentale del Piemonte, Liguria e Valle D'Aosta, Turin, Italy. ${ }^{2}$ Universita' Degli Studi di Torino, Turin, Italy. ${ }^{3}$ Azienda Sanitaria Locale del Verbano Cusio Ossola (ASL VCO), Omegna, Italy. ${ }^{4}$ Azienda Sanitaria Locale di Asti (ASL AT), Asti, Italy. ${ }^{5}$ Azienda Sanitaria Locale 1 Imperiese (ASL1 Imperiese), Sanremo, Italy. ${ }^{6}$ Istituto Zooprofilattico Sperimentale della Sicilia "A. Mirri", Palermo, Italy.

Received: 14 August 2020 Accepted: 23 January 2021

Published online: 05 March 2021 


\section{References}

1. Alciati S, Belligni E, Del Colle S, Pugliese A. Human infections tick-transmitted. Panminerva Med. 2001:43(4):295-304.

2. Biggs HM, Behravesh CB, Bradley KK, Dahlgren FS, et al. Diagnosis and management of tickborne Rickettsial diseases: Rocky Mountain spotted fever and other spotted fever group Rickettsioses, Ehrlichioses, and Anaplasmosis—United States. MMWR Recomm Rep. 2016;65(2):1-44.

3. van Oort BEH, Hovelsrud GK, Risvoll C, Mohr CW, Jore S. A mini-review of ixodes ticks climate sensitive infection dispersion risk in the Nordic Region. Int J Environ Res Public Health. 2020;17:5387. https://doi. org/10.3390/ijerph17155387.

4. Blanda V, Torina A, La Russa F, D'Agostino R, Randazzo K, Scimeca S, et al. A retrospective study of the characterization of Rickettsia species in ticks collected from humans. Ticks Tick Borne Dis. 2017;8(4):610-4. https://doi. org/10.1016/j.ttbdis.2017.04

5. Capelli G, Ravagnan S, Montarsi F, et al. Occurrence and identification of risk areas of Ixodes ricinus-borne pathogens: a cost-effectiveness analysis in north-eastern Italy. Parasites Vectors. 2012;5:61. https://doi. org/10.1186/1756-3305-5-61.

6. Castro LR, Gabrielli S, lori A, et al. Molecular detection of Rickettsia, Borrelia, and Babesia species in /xodes ricinus sampled in northeastern, central, and insular areas of Italy. Exp Appl Acarol. 2015;66:443-52. https://doi. org/10.1007/s10493-015-9899-y.

7. Choi YJ, Jang WJ, Ryu JS, Lee SH, Park KH, Paik HS, et al. Spotted fever group and typhus group Rickettsioses in humans, South Korea. Emerg Infect Dis. 2005;11(2):237-44.

8. D'Agaro P, Martinelli E, Burgnich P, Nazzi F, Del FS, lob A, et al. Prevalence of tick-borne encephalitis virus in Ixodes ricinus from a novel endemic area of North Eastern Italy. J Med Virol. 2009;81:309-16. https://doi. org/10.1002/jmv.21389.

9. Dantas-Torres F, Chomel BB, Otranto D. Ticks and tick-borne diseases: a one health perspective. Trends Parasitol. 2012;28(10):437-46. https://doi. org/10.1016/j.pt.2012.07.003.

10. De Meneghi D. Wildlife, environment and (re)-emerging zoonoses, with special reference to sylvatic tick-borne zoonoses in North-Western Italy. Ann Ist Super Sanita. 2006;42(4):405-9.

11. Dumler JS, Choi KS, Garcia-Garcia JC, Barat NS, et al. Human granulocytic anaplasmosis and Anaplasma phagocytophilum. Emerg Infect Dis. 2005; 11:1828-34.

12. Estrada-Peña A, Mihalca AD, Petney TN. Ticks of Europe and North Africa. A guide to species identification. Berlin: Springer International Publishing; 2017

13. Floris R, Yurtman AN, Margoni EF, Mignozzi K, Boemo B, Altobelli A, et al. Detection and identification of Rickettsia species in the Northeast of Italy. Vector Borne Zoonotic Dis. 2008;8(6):777.

14. Gage KL, Burkot TR, Eisen RJ, Hayes E. Climate and vectorborne diseases. Am J Prev Med. 2008;35:436-50. https://doi.org/10.1016/j.amepr e.2008.08.030.

15. Germanakis A, Chochlakis D, Angelakis E, Tselentis Y, Psaroulaki A Rickettsia aeschlimannii infection in a Man, Greece. Emerg Infect Dis. 2013:19:1176-7. https://doi.org/10.3201/eid1907.130232.

16. Heyman P, Cochez C, Hofhuis A, van der Giessen J, Sprong H, Porter S R, Losson B, Saegerman C, Donoso-Mantke O, Niedrig M, Papa A. A clear and present danger: tick-borne diseases in Europe. Expert Rev Anti-infect Ther. 2010;8(1):33-50. https://doi.org/10.1586/eri.09.118.

17. Černý J, Lynn G, Hrnková J, Golovchenko M, Rudenko N, Grubhofer L. Management options for Ixodes ricinus-associated pathogens: a review of prevention strategies. Int J Environ Res Public Health. 2020;17(6):1830 https://doi.org/10.3390/ijerph17061830.

18. Jaenson TGT, Lindgren $\mathrm{E}$. The range of Ixodes ricinus and the risk of contracting Lyme borreliosis will increase northwards when the vegetation period becomes longer. Ticks Tick Borne Dis. 2011;2(1):44-9. https://doi. org/10.1016/j.ttbdis.2010.10.006.

19. Kernif T, Leulmi H, Raoult D, Parola P. Emerging tick-borne bacterial pathogens. Microbiol Spectr. 2016. https://doi.org/10.1128/microbiolspec.

20. Madeddu G, Mancini F, Caddeo A, Ciervo A, et al. Rickettsia monacensis as cause of Mediterranean spotted fever-like illness, Italy. Emerg Infect Dis. 2012;18(4):702-4. https://doi.org/10.3201/eid1804.111583.

21. Manilla G. Acari Ixodida. Fauna d'Italia, vol. 36. Bologna: Calderini; 1998
22. Massung RF, Slater KG. Comparison of PCR assays for detection of the agent of human granulocitic erlichiosis Anaplasma phagocytophilum. J Clin Microbiol. 2003:41:717-22.

23. Roselli MA, Cady SM, Lao S, Noden BH, Loss SR. Variation in tick load among bird body parts: implications for studying the role of birds in the ecology and epidemiology of tick-borne diseases. J Med Entomol. 2020;57(3):845-51. https://doi.org/10.1093/jme/tjz228.

24. Nilsson K, Lindquist O, Liu AJ, Jaenson T, et al. Rickettsia helvetica in /xodes ricinus ticks in Sweden. J Clin Microbiol. 1999:37(2):400-3.

25. Nilsson K. Septicaemia with Rickettsia helvetica in a patient with acute febrile illness, rash and myasthenia. J Infect. 2009;58(1):79-88.

26. Nilsson K, Elfving K, Pahlson C. Rickettsia helvetica in patient with meningitis, Sweden, 2006. Emerg Infect Dis. 2010;16:490-2. https://doi. org/10.3201/eid1603.090184

27. Oteo José A, Portillo A. Tick-borne rickettsioses in Europe. Ticks Tick-borne Dis. 2012;3(5-6):271-8. https://doi.org/10.1016/j.ttbdis.2012.10.035.

28. Otranto D, Dantas-Torres F, Giannelli A, Latrofa M, et al. Ticks infesting humans in Italy and associated pathogens. Parasites Vectors. 2014;7(1):328. https://doi.org/10.1186/1756-3305-7-328.

29. Parola P, Paddock CD, Socolovschi C, Labruna MB, et al. Update on tick-borne rickettsioses around the world: a geographic approach. Clin Microbiol Rev. 2013;26(4):657-702. https://doi.org/10.1128/CMR.00032 -13.m.

30. Pintore MD, Ceballos L, Iulini B, Tomassone L, Pautasso A, Corbellini D, et al. Detection of invasive Borrelia burgdorferi strains in north-eastern Piedmont, Italy. Zoonoses Public Health. 2015;62:365-74.

31. Rauter C, Hartung T. Prevalence of Borrelia burgdorferi sensu lato genospecies in Ixodes ricinus ticks in Europe: a metaanalysis. Appl Environ Microbiol. 2005;71(11):7203-16. https://doi.org/10.1128/ AEM.71.11.7203-7216.2005.

32. Santos-Silva MM, Beati L, Santos AS, De Sousa R, et al. The hard-tick fauna of mainland Portugal (Acari: Ixodidae): an update on geographical distribution and known associations with hosts and pathogens. Exp Appl Acarol. 2011;55:85-121.

33. Scarpulla M, Barlozzari G, Marcario A, Salvato L, Blanda V, De Liberato C, et al. Molecular detection and characterization of Spotted Fever Group rickettsiae in ticks from Central Italy. Ticks Tick-borne Dis. 2016;7(2016):1052-6. https://doi.org/10.1016/j.ttbdis.2016.06.003.

34. Scharlemann JP, Johnson PJ, Smith AA, Macdonald DW, Randolph SE. Trends in ixodid tick abundance and distribution in Great Britain. Med Vet Entomol. 2008;22(3):238-47. https://doi.org/10.111 1/j.1365-2915.2008.00734.x.

35. Seltzer EG, Gerber MA, Cartter ML, Freudigman K, Shapiro ED. Long-term outcomes of persons with Lyme disease. JAMA. 2000;283(5):609-16. https ://doi.org/10.1001/jama.283.5.609.

36. Skotarczak B, Wodecka B, Cichocka A. Coexistence DNA of Borrelia burgdorferi sensu lato and Babesia microti in Ixodes ricinus ticks from north-western Poland. Ann Agric Environ Med. 2002;9(1):25-8.

37. Smith FD, Ballantyne R, Morgan ER, Wall R. Prevalence, distribution and risk associated with tick infestation of dogs in Great Britain. Med Vet Entomol. 2011;25(4):377-84. https://doi.org/10.1111/j.1365-2915.2011.00954 $x$.

38. Sonenshine DE. Range expansion of tick disease vectors in North America: implications for spread of tick-borne disease. Int J Environ Res Public Health. 2018;15(3):478. https://doi.org/10.3390/ijerph15030478.

39. Starck MJ, Mehnert L, Biging A, Bjarsch J, Franz-Guess S, Kleeberger D, et al. Morphological responses to feeding in ticks (Ixodes ricinus). Zoological Letters. 2018;4:20.

40. Tagliapietra V, Rosà R, Arnoldi D, Cagnacci F, et al. Saturation deficit and deer density affect questing activity and local abundance of Ixodes ricinus (Acari, Ixodidae) in Italy. Vet Parasitol. 2011;183(1-2):114-24.

41. Wilhelmsson $P$, Lindblom $P$, Fryland $L$, et al. Ixodes ricinus ticks removed from humans in Northern Europe: seasonal pattern of infestation, attachment sites and duration of feeding. Parasites Vectors. 2013;6:362. https:// doi.org/10.1186/1756-3305-6-362.

\section{Publisher's Note}

Springer Nature remains neutral with regard to jurisdictional claims in published maps and institutional affiliations. 